\title{
The Creation of Economic Zones as Instruments for the Attraction of Fdis and for the Promotion of Exports: Case of Kosovo
}

\author{
Prof.Ass.Dr. Hysni TERZIU \\ Public University of Prizren "UKSHIN HOTI" \\ MSc Besnik Terziu
}

Abstract

\begin{abstract}
Various theories and studies suggest that the Economic Zones are actual and very important instruments for the attraction of the FDIs and for the promotion of exports. However, on the other side, there are pro and against economic arguments regarding the opinions for the creation of economic zones, suggesting also that the adoption of such schemes is not always profitable. Economic Zones are a solution for the whole region because it creates demand for a variety of jobs that would encourage technological education and that would promote economic growth for the existing population in the areas that are currently attracting new residents. For the reason that benefits arising from the making of Economic Zones are of unique value and very important for the country in which they are established, therefore on this it is based the decision of many countries to adopt the schemes for the Economic Zones. However, even more important is to know the other side of the coin, i.e. limitations and obstacles to achieve the expected benefits, problems and costs which in many cases are unforeseen or underestimated. In addition to the abovementioned benefits for the country as a whole, the state must also perform an analysis of costs and revenues, so to evaluate the effects that would have on the state budget the establishment and management of these areas and its ability to realize other public investments. This paper also provides details of benefits and problems arising from implementation of Economic Zones, such as: the potential growth of foreign exchange earnings; the effect of income taxes; transfer of technology, knowledge and relationships in the supply chain; employment effects on local and national economy; as well as the benefits from the development of human capital. In the focus of this paper are the policies and the structural and institutional reforms of Kosovo on the creation of appropriate conditions for the attracting of FDls and for the promotion of exports. This for the fact that Kosovo is among the countries with the lowest indicators of exports regardless of the kind of products or services. Therefore, the establishment of economic zones, except that are very important instruments for the promotion of exports, they will make also possible the generation of new work places that Kosovo needs for the fact that unemployment is very pronounced. Various cases of creating Economic Zones in Kosovo are presented in the final part of the paper. The purpose of this paper is that in both in practice and in theory to treat the economic zones from a critical perspective regarding their main benefits and to find the factors that would minimize the positive impact on the host country.
\end{abstract}

Keywords: Economic Zones, exports, impact, jobs, employment, development, Kosovo.

\section{Introduction}

When we talk regarding the creation of Economic Zones, as important instrument for economic development, then we say that the presentation of Economic Zones is important for all the involved parties: for the investor, the economy and the region as $w$ whole. For the investor is also beneficial as is able to use the comparative advantage of the economy (e.g. cheap labor) technological and scientific infrastructure, free trade agreements, initiatives and priorities from Economic Area itself, as a business park, industrial park, technology park, or effective business incubator.

It is suggested, that the balance of payments of the economy is improved as a result of increased trade volume and export revenues. The economic growth is stimulated as a result of the growth of value added (wages and taxes) and as a result of mutual ties of industry, trade and local services to international markets.

From this point of view, Economic Zones are a region-wide solution as it creates higher demand for a variety of jobs that would encourage technological education and that would promote economic growth for the existing population in areas that are currently on site and may also attract young people ${ }^{1}$. So from this we can say that all the above mentioned benefits do

1 Eldar, M., Towards Economic Growth and Independence: Establishment of Free Export Processing Zones in Israel, Institute for Advanced Strategic and Political Studies, Jerusalem, No. 10, 1992 
hold and are very important because based on them are made the decision from many countries wheather or not to adopt Economic Zones schemes.

However, even more important it is to know the other side of the coin, ie. limitations and obstacles to achieve the expected benefits, problems and costs that in many cases are unforeseen or underestimated. Especially in the planning stage of the economic zones, it is necessary to carry out a realistic objective analysis of the costs and of the expected benefits.

Before treating some of the main benefits and costs associated with the implementing process of the economic zones we have to consider three main problems:

- Firstfully, the cause and effect relationship in the case of benefits which come from the creation of economic zones, it is never very clear. Even in the case when the investment or the employment levels increase after the implementation of zones, this does not necessarily mean that this increase was due to the creation of economic zones. This can lead to the overestimation of the benefits.

- Secondly, the analysis does not consider the distribution of costs and benefits, such as increased employment which belongs only to the host country, while the growth of foreign exchange earnings, at a time that is expected to bring benefits to the host country, can bring more benefits to the beneficiary country where such income goes in the form of profits.

- Thirdly, some benefits are intangible and difficult to measure, such as technology transfer, "flow" of knowledge, etc ${ }^{1}$.

\section{The expected benefits and the problmes coming from the implementation of Economic Zones}

\subsection{Growth potential in the foing direct earnings}

One of the main benefits from the establishment of an economic zone are the expected foreign exchange earnings. In fact, this is not the correct criteria for assessing the success or failure of the zone, but can help many economies with low incomes to meet their needs for imports and to provide the state with the funds needed for development (public investment, to support policies for the development of local industries, etc.).

However, the benefits from the increased foreign exchange may be overestimated. According to Warr $(1989)^{2}$, when companies operate in the zone are mainly with foreign capital, it is likely that during the process of buying the inputs, they choose more the international supplier of low cost, instead of local suppliers. Especially in the case when international companies follow a flexible strategy- "international mobility of their manufacturing operations", long-term relationship with local suppliers would go into conflict under this strategy. If we include in the analysis the fact that most activities in the economic areas have low added value, then the result suggest that the value of net exports will be substantially lower than the value of gross exports.

\subsection{The effect of income from tax / tax losses}

In many cases, establishment of economic zones means providing fiscal support from the host country to attract FDI. Some researchers think that the losses of revenue from taxes, due to the fiscal facilitation, are lower than the benefits provided by the creation of employment and foreign exchange earnings. They note that in any regime, taxes such as customs duties are still low, that is why the losses will not be significant. There exist several arguments that weaken this reasoning.

Firstly, the costs of establishing economic zones are not consisted only from the missing incomes from taxes, even to say the largest share of these costs is occupied from spending on infrastructure investments, services, facilities, management of the zone as well as opportunity costs of public funds investment on Economic Zones.

\footnotetext{
1 Totoni A., Zonat ekonomike si instrumenta për tërheqjen e IHD-ve dhe nxitjen e eksporteve - argumenta ekonomike pro dhe kundër, Ekonomia dhe tranzicioni. - Nr. 1, 2009, page 46 - 58. XVII

2 Warr, P., Export Processing Zones - The Economics of Enclave Manufacturing, World Bank Research Observer. 4, 65-88, 1989
} 
Secondly, in many developing countries, taxes, fees and other indirect duties are an important source of income for the state. In these countries, the state in many cases is incapable to implement the plan of collecting fiscal obligations due to the existence of the informal economy. Being at a disadvantaged position, the situation would worsen if the state will give up from a part of this revenue due to tax incentives. This is also why a number of international organizations (EU, IMF, etc.) discourage the use of fiscal incentives by developing countries.

\subsection{Catalyst effect of FDI, transfer of technology, knowledge and relationships in the supply chain}

The effect of FDls goes beyond the attraction of the necessary capital, whether in the form of cash or materialized in the form of machinery and equipment. Successful companies in the zone serve as well as examples or models from which local enterprises and entrepreneurs can learn and "copy". Rhee and Belot (1990) refers to the economic zones as "catalyst" because they initiate and develop production for export (mainly non-traditional exports) by combining their technical, managerial and marketing know-how to access the global markets and the advantages that the host country offers.

With regard to the transfer of technology and knowledge, this can be accomplished in several ways, such as: through links in the forward supply chain (from the buyer to the vendor), as well as through formal trainings or through the transfer of the personnel from a foreign company operating within the zone to the domestic companies operating abroad.

Backward links in the supply chain occur when a foreign company buys an input within the area and a local company sells this input. This also happens when a foreign company subcontracts a part of the production to a local company outside the zone. The technology transfer often occurs because buyers tend to help the retailers on the achievements of the required quality specifications of the product. Also the backward links in the supply chain are difficult to express in quantitative form, but they can be evaluated approximately by calculating the percentage of raw materials purchased within the country, or by calculating the percentage of the costs incurred in the country against total output.

Transfer of technology and knowledge happens also in those cases when the labor force is transferred from a foreign company to a local company within the zone. Especially for middle-class managers are offered good opportunities, because after they enrich their experience by working with the foreign companies in economic zones, they can be removed to create their own businesses (Khemani, 2007).

However, the positive effects of technology transfers can be limited. According to Warr (1989), foreign enterprises focus on the research-development activities and on the manufacturing processes of advanced technologies in the home country. Therefore technological processes that are carried in the economic zones are usually of low-tech, labour-intensive and employs less skilled workforce.

\subsection{The employment effects in local and national economy}

Since they rely on labour-intensive activities, economic zones are considered as a source for employment generation. The creation of new jobs is considered as one of the main goals and the most important contributions of the economic zones for the local economy. This goal is based on two assumptions:

The first is that the country has high unemployment rates. This is a significant reason until the excess supply of labor is absorbed. Thereafter, the host country face a tight labor market and as such labor costs start to rise. Certainly, the rising of the labor costs is translated into higher incomes for the work and the improvement of living standards for workers. On the other hand, this makes companies that operate in the zone to have local exports less competitive in the world market. This can lead to the loss of new investments, or, even worse, the leave of current investors to countries that offer lower variable cost.

The second assumption is related to the fact that the creation of new jobs will ease the unemployment problems. Economic zones have created a significant number of new jobs, especially in those cases when they have been managed and developed successfully. However there are cases when they have not achieved the expected goals due to poor choice of dislocation or due to unsatisfied infrastructure that can lead to the partial population of the economic zone. 
Table 1: Direct employment in economic zones

\begin{tabular}{|c|c|c|}
\hline Region & Direct employment (million) & $\begin{array}{l}\text { Share to total employment } \\
(\%)\end{array}$ \\
\hline Asia/ Pacific & 35 & 2.3 \\
\hline North and South America & 2.1 & 1.2 \\
\hline Central Europe / Eastern \& Central Asia & 0.2 & 0.001 \\
\hline Middle East \& North Africa & 1.1 & 1.5 \\
\hline Sub-Saharan Africa & 0.7 & 0.2 \\
\hline
\end{tabular}

Source: Khemani, 2007

An interesting phenomenon is the employment of mainly female works in majority of the economic zones, which has had an important impact on the general unemployment. Initially, it was thought that these zones would have a positive impact on the reduction of unemployment, mainly among men. But looking for a less skilled workforce, these zones have had an unexpected effect, employed a considerable high number of women. They were seen as the most suitable candidates for unskilled jobs because they newly entered to the labour market and have lower demands for payments compared to men. The percentage of women to the total workforce vary from $60 \%$ to $80 \%$ (Kusago and Tzannatos, 1998), however, this trend is changing with the emergence of new industries in Economic Zones.

\section{The revenues and expenditures for the state}

In this regard, briefly will be discussed the impact of the creation of an Economic Zone on state revenues and expenditures.

The revenues generated for the state, relate mainly on the increase of the tax volume, fees and other charges due to the increase of economic activity. So, although companies that operate in these zones are subject to a more favourable fiscal regime (with lower tax rates) compared to local companies, have a positive final effect on incomes that enter into state budget. Positive contributions would have also the payments that are collected from leasing land and facilities, or by issuing permits, licenses, etc.

With regard to expenses, usually are necessary large public investments for infrastructure, particularly in those zones which are funded by the state. Infrastructure costs, including here public services such as water and electricity, can be too high especially in the cases when the expected benefits on employment and investments are delayed. 
Table 2: Revenues and costs of state from developing these areas

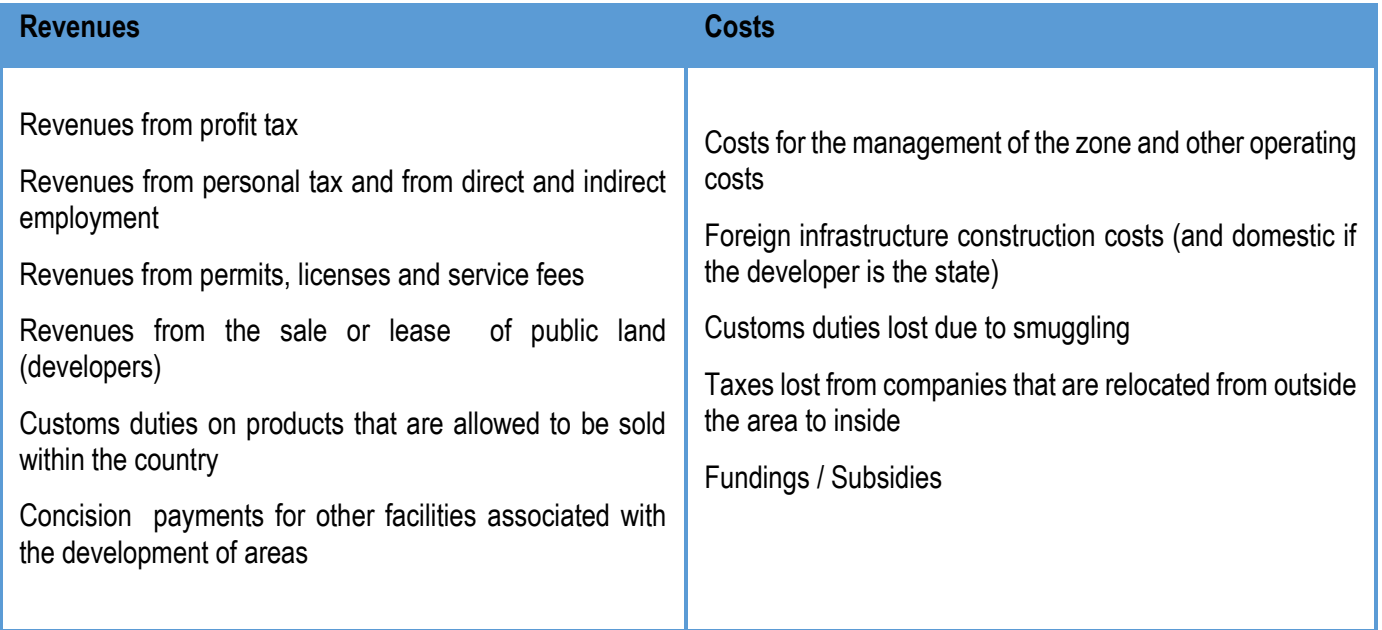

Source: Khemani, 2007

The use of various fiscal incentives such as exemption from tariff payment, income tax and other tax exemptions may have a negative impact on state revenues. Although fiscal tendencies stimulate the investments, there is no empirical evidence regarding their effectiveness in terms of costs. Governments that provide these fiscal incentives, should assess time by time how appropriate they are and the economic benefits derived from them by comparing with the costs, to assess their long-term impact on the allocation of resources, etc (OECD, 1996).

\section{Economic Zones in Kosovo}

An economic zone is a territory that has a special economic status and it can be in a form of free zone or as industrial park, as defined below.

Free zone is an area, with defined land, buildings and other real properties, with productive, trade or service activities that is estimated as part of the customs territory of the Republic of Kosovo, separated from this territory, in terms of fiscal and customs regime, and governed in accordance with the provisions of this law.

On the other hand, the industrial park is an area, divided into plots, in accordance with a general plan, equipped with the necessary infrastructure such as roads, public transport and services, with or without industrial buildings, intended for industrial development.

As Developer is any legal person, licensed, local or foreign, who builds, administers and monitors the functioning of economic zones in accordance with the provisions of this law.

Operator is any legal person, local of foreign, who operated insides he boundaries of the economic zone, in the quality of a manager, through a contractual relationship concluded between him and the developer, a relationship which is not subject to this law.

The user is the person, individual or legal, local or foreign, in an economic activity within the economic zone, in accordance with the provisions of this law ${ }^{1}$.

\footnotetext{
${ }_{1}^{1}$ Law No. 02/L-5 on the Supervision of Small and Medium Enterprises (SMS), March, 2005.
} 


\section{Legalization of Economic Zones}

Law on the Economic Zones and the legal acts coming from this law, with the purpose for their normal operation, foresees the legalization of economic zones. There have been developed all the necessary procedures foreseen by the legislation in force such as necessary forms and applications dealing with the zones and that will be used for obtaining permissions from the relevant institutions.

\section{Economic codes for Economic Zones}

Economic codes are defined and are prepared the Payment Forms / Invoices for payment, which will be used for payment and which are provided on the basis of Administrative Instruction no. 2009/26, in the case of the application from the interested parties for the establishment of Economic Zones.

\section{Legalization of Economic Zone in Drenas}

After the completion of the documentation, in conformity with the legislation under the Law on Economic Zones and after the recommendations from the Minister of Ministry of Trade and Industry to create an economic zone in Drenas, the Prime Minister with the Decision No. 06/140, dated. 18.08.2010 announced the Drenas Business Park as an economic zone.

\section{Legalization of Economic Zone - Technological Park in Skenderaj}

After submitting the application by the municipality of Skenderaj, it was analyzed the documentation whether it is in comfort with the legislation. After the evaluation of the documentation, was prepared the file and was forwarded to the issuance of the decision for legalization. Economic Zone, Technological Park in Skenderaj was announced by the Prime Minister through the decision no. 07/140, dated. 18. 08. 2010.

\section{The Programme for the management of Economic Zones}

During this year, there were drafted the terms of reference for designing the program for the management of the economic zones. Then the economic operator was contracted and started the designing of this program with the study visit in Slovenia. So far, there has compiled over $60 \%$ of the program, while the rest goes to the dynamic plan in 2011.

\section{Package for the facilitations for businesses that operate within the Economic Zones in Kosovo}

At the regular meeting of the SME Advisory Board on date 02.07.2010, has been issued the decision on the formation of the group "to create incentives for local businesses in economic zones". The working group is represented by relevant institutions and business associations in Kosovo. This working group held regular meetings and has prepared a draft package for facilitation, a draft that will be presented to the Advisory Board in its next meeting ${ }^{1}$.

\section{The creation of Business Park in Mitrovica}

In Mitrovica, the Ministry of Trade and Industry has allocated a budget with the amount of 155,000 Euros on the construction of an industrial park in this Municipality. The selected location is made on the basis of a feasibility study which was conducted by the Department Private Sector Development, conditions which offered by the Municipal Assembly of Mitrovica. As additional criteria for this municipality are taken in terms of regional development and multi-ethnic character that this municipality possesses.

The Municipal Assembly of Mitrovica has offered a land with an area of 350.86 hectares, which has been owned before by the municipality, and a budget in the amount of 10,000 Euros. The Ministry of Trade and Industry (now on referred ad MTI) has announced a tender for the construction of a part of the total infrastructure because the budget needed for the completion of the whole infrastructure was limited. This phase of construction of this infrastructure is now in the final stage and the MTI is in talks with European Agency for Reconstruction (EAR) to receive financial support from the agency in order to complete all the infrastructural works.

\footnotetext{
${ }^{1}$ Agency for the Support of Small and Medium Enterprises (SME), MTI, Kosovo.
} 
From the Municipal Assembly of Mitrovica has been made the selection of beneficiary companies for the Business Park.

Position - The Park is located in the north-eastern part of the city at a distance of $200 \mathrm{~m}$ from the main road of the city and in the north-western part is bordered from the city industrial area.

Spaces (parcels) - On the location are foreseen 21 plots for the placement of businesses. Parcel sizes vary from $162 \mathrm{~m}^{2}$ to $411 \mathrm{~m}^{2}$. Activities that are conducted by the businesses in the park deal with manufacture textile, wood elements, construction, traditional crafts and food, etc.

Statute of the parcels- in the Business Park parcels will be in service without rent for a period of 10 years, and then will be applied reasonably renting prices in comfort with the market ${ }^{1}$.

Figure 1: Construction phase of the industrial park (international) in Drenas

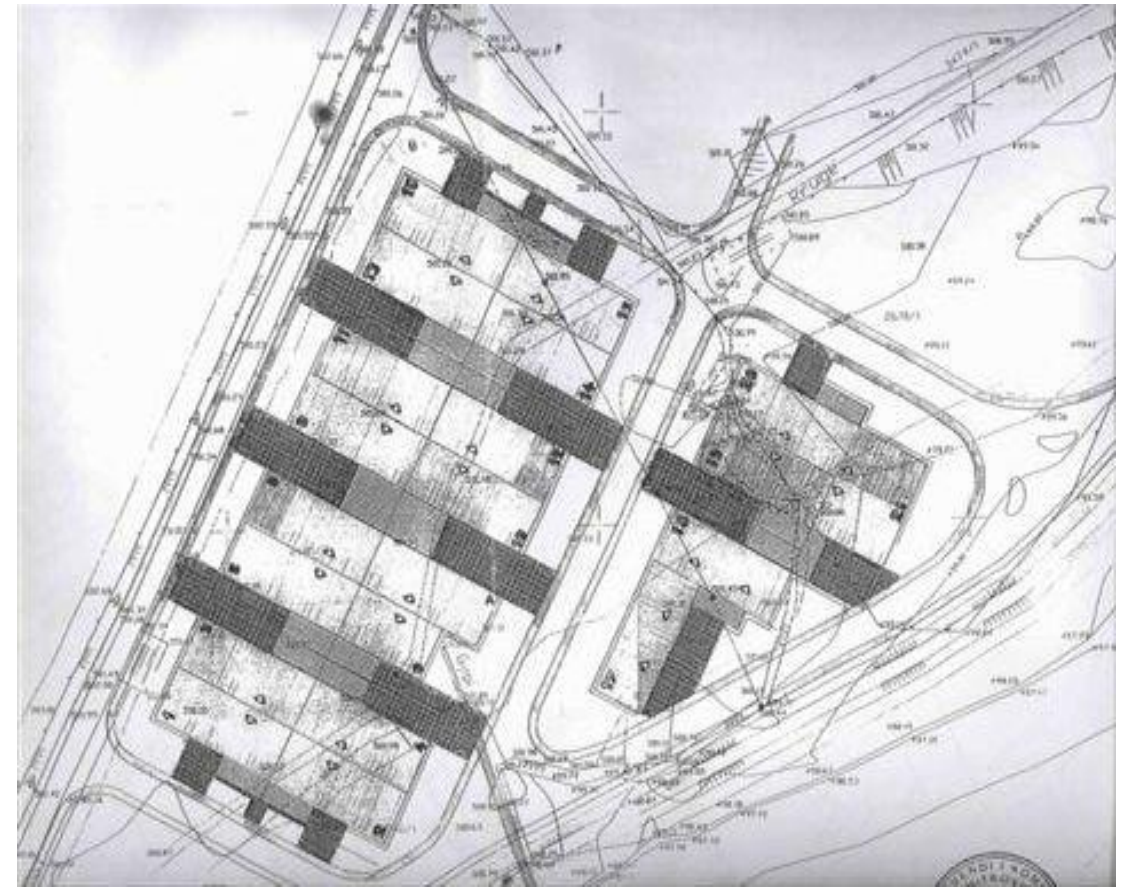

Source: MTI

\section{Industrial Park (national) in Drenas}

The location of the industrial park is located in the Upper Koretice in the Municipality of Drenas. This place is known as "Spring of the King" and is found along the road Prishtina - Peja at the 16th kilometre. In relation to Kosovo, it is in a radius of $100 \mathrm{~km}$.

The reason that made the MTI to implement this project exactly in this place, which already has a feasibility study from the AER, it is because near this place is located the International Airport of Prishtina, the railroad, the highway Durres-Prishtina. This site includes an area of 27 ha and is owned by the Municipality of Drenas.

\footnotetext{
${ }^{1}$ Agency for the Support of Small and Medium Enterprises (SMS), MTI, Kosovo.
} 
For its building, in 2005, the MTI has allocated $€ 650,000$ while the European Agency for Reconstruction has been supporting this project with a feasibility study and has designed the infrastructure of the Industrial Park.

The Park is now in the infrastructure design phase, and we expect that as soon as we designed phase to finish, then to be announced tender for construction of infrastructure,

Distribution of parcels will be subject to interest and scope of investors' operation. ${ }^{1}$

Figure 2: The Business Park in the Municipality of Drenas

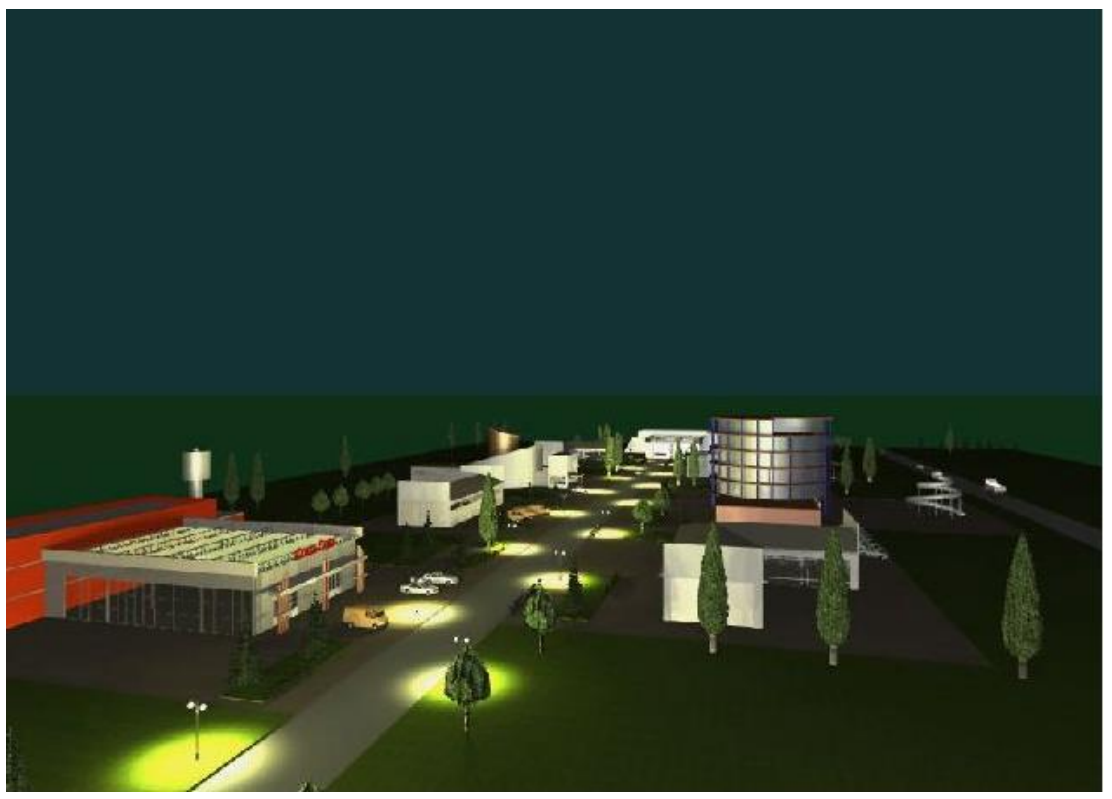

Source: MTI

\section{Business Park in Drenas (BPD)}

Regular meetings of the Supervisory Board have been held for the management of BPD. In the meetings, were presented regular reports on the progress of the work on capital projects, dealing with the Business Park in Drenas. Also within the meetings, have been taken necessary decisions regarding the solution of the problems occurred during the execution of projects. In meetings of the Board are also presented information on the documents for competitions and evaluations that have been conducted to establish businesses in BPD

\section{The placement of businesses in BPD - Competition, the second and third phase}

During 2010, were conducted two competition phases to place businesses in BPD, namely the: phase two and phase three.

Second Phase- Documents have been prepared to publish the competition, phase two, placement of businesses in BPD. The contest was announced on 04.02.2010 and was opened for 30 days. At this stage, the interested businesses have applied and the total number of applicants was 21 businesses. However, only 11 businesses benefited. After this, the contracts have been signed.

\footnotetext{
${ }^{1}$ Agency for the Support of Small and Medium Enterprises (SMS), MTI, Kosovo.
} 
Third Phase- Documents have been prepared to declare the competition, phase three, placement of businesses in BPD. The competition was announced in June 2010 and continues to be open for interested application. At this stage 8 contracts have been signed with businesses and by the end of this phase, is concluded that all parcels in the Business Park in Drenas are fulfilled. In addition, another 7 businesses have remained on the waiting list, in case of withdrawal of any business.

\section{Building Business Objects in the BPD}

Within the published competitions for the three phases in order to establish businesses in BPD, a total of 37 contracts were signed with the businesses that have applied. Until now, has started the construction of 13 businesses while the rest are in preparation for the construction of the facilities ${ }^{1}$.

Even though the businesses were obliged, under the contract, to begin the construction of the buildings and for this issue many time to them have been forwarded numerous letters to respect the contract, this part of the businesses still declare that are still in preparation.

For not respecting the deadlines for the start of works, contracts with 6 businesses of the first phase of the application have been breached.

\section{Conclusions}

Economic Zones are instruments with value for economic development to the investors, for the economy of the host country and also for the region where they are created. However in some cases, the benefits derived from those zones are not those expected, and it can happen that the costs associated with the establishment of the zones may result higher than the benefits.

For this reason, especially in the planning phase of economic zones, it is necessary to carry out a realistic analysis of costs and expected benefits.

This analysis may be difficult because of uncertain cause and effect relationships between the creation of economic zones and their effects, the uncertainty in the distribution of costs / benefits between host country and investors, as well as because of the difficulty of measuring the intangible benefits such as technology transfer, "flow" of knowledge etc. which are among the most valuable benefits of Economic Zones.

Among the main benefits can be mentioned: higher currency incomes, growth of gross exports, creation of new work places, higher wage levels, opportunities to train employees, managers and supervisors, ensures effects of the catalysts and demonstration, etc.

The main problems relate to the fact that some of the above benefits can be overstated. The net exports may be lower, job security may be lower, the skills that the employee benefits and technologies may be of low-tech, lost income from taxes /fees and the opportunity cost of public investment in relation to the area. So all these disadvantages can be high, may cause environmental damage and safety problems at work due to the neglecting of laws and insufficient supervision by the government.

These problems and their causes must be taken into consideration by the governments when planning the economic zones in order to limit the negative effects, to stop inhibitory factors and to maximize the expected benefits.

In addition to the above mentioned benefits for the country as a whole, the state must also perform an analysis of costs and revenues, so to evaluate the effect that the establishment and management of areas will have on the state budget and its ability to realize other public investment .

\footnotetext{
${ }^{1}$ Agency for the Support of Small and Medium Enterprises (SMS), MTI, Kosovo.
} 


\section{Summary}

According to different authors and other supporters of the creation of Economic Zones as instruments for economic development, the presentation of these economic zones is of value to all involved parties such as: the investor, the economy and the overall region. The benefits mentioned above are of high importance, because based on them are made decisions by many countries to adopt schemes for the creation of economic zones.

However, even more important it is to know the other side of the coin, i.e. limitations and obstacles to achieve the expected benefits, problems and costs which in most of the times are unforeseen or underestimated. Especially in the planning stage of the economic zones, it is necessary to carry out a realistic analysis of costs and expected benefits. So to conclude, this paper tried to address from a critical perspective the main benefits of economic zones by highlighting the deficiencies and the factors that minimize their positive impact especially on the host country.

\section{References}

[1] Eldar, M., Towards Economic Growth and Independence: Establishment of Free Export Processing Zones in Israel, Institute for Advanced Strategic and Political Studies, Jerusalem, No. 10, 1992

[2] Facchini, G., Willmann, G., The Gains from Duty Free Zones, Journal of International Economics, 49, page 403-412, 1999

[3] Khemani, R.S., Competition Policy and Promotion of Investment, Economic Growth and Poverty Alleviation in Least Developed Countries, FlAS Occasional Papers No. 19, 2007, Washington DC, ISBN: 978-0-8213-7318-7

[4] FIAS, Special Economic Zones: Performance, Lessons Learned, and Implications for Zone Development, The World Bank April 2008, Washington DC

[5] Hamada, K., And Economic Analysis of the Duty-Free Zone, Journal of International Economics, 4: 225-241, 1974

[6] Perman, S., Duvillier, L., David, N., Eden, J., Behind the brand names: working conditions and labour rights in export processing zones, ICFTU, Geneva: International Confederation of Free trade Unions, December 2004

[8] ICFTU, Export Processing Zones: Symbols of Exploitation and a Development Dead-End, Sep 2003, Brussels

[9] Kusago, T., Tzannatos, Z., Export Processing Zones: A Review in Need of Update, Social Protection Discussion Paper No. 9802, January 1998, Washington DC: The World Bank

[101 OECD. Trade. Emblovment and Labour Standards: A Study of Core Workers' Rights and International Trade, Sep 1996, OECD Publishing, ISBN: 9789264152700 , Paris

[11] Rhee, Y.W., and T. Belot, T., Export Catalysts in Low-Income Countries- A Review of Eleven Success Stories, World Bank biscussion Papers, 72., 1990, World Bank, Washington DC

[12] Romero, A., Labour standards and EPZ; Situation and pressures for change, Development Policy review, 13, 247-276, 1995

[13] UNIDO, Export Procesing Zones in Developing Countries, UNIDO Working Papers on Structural Changes, No.10. UNIDO International Centre for Science and High Technology, Vienna, 1980 [14] Warr, P., Export Processing Zones - The Economics of Enclave Manufacturing, World Bank Research Observer. 4, 65-88,
1989

[151 Totoni A.. Zonat ekonomike si instrumenta bër tërheaien e IHD-ve dhe nxitjen e eksporteve - argumenta ekonomike pro dhe kundër, Ekonomia dhe tranzicioni. - Nr. 1, 2009, page 46 - 58. XVII

[16] Law No. 02/L-5 on the Supervision of Small and Medium Enterprises (SMS), March, 2005

[17] Agency for the Support of Small and Medium Enterprises (SMS), MTI, Kosovo 